\title{
Mechanical and Bond Characteristics of SRP and CFRP Reinforcement - A Comparative Research
}

\author{
G.J. Mitolidis ${ }^{1}$, T.N. Salonikios ${ }^{2}$ and A.J. Kappos*,1 \\ ${ }^{1}$ Civil Engineering Department, Aristotle University of Thessaloniki, 54124 Thessaloniki, Greece and ${ }^{2}$ Structural Divi- \\ sion, Institute of Engineering Seismology and Earthquake Engineering, Thessaloniki, Greece
}

\begin{abstract}
The paper reports results from the two first phases of an experimental research programme on the behaviour of concrete beams strengthened with reinforced polymers. The work presented here refers to results from tensile tests of SRP (Steel Reinforced Polymer) and CFRP (Carbon Fibre Reinforced Polymer) strips, with and without epoxy resin, as well as bond tests of polymer strips glued on rectangular concrete prisms. Concrete mix for the prisms was designed with a view to simulating the concrete strength that was used in Greece during the period from 1960 to 1980 for residential and office buildings. Various configurations of SRP and CFRP strips were bonded to ten rectangular concrete prisms using epoxy resin. The main parameters of the tests were the fibre type (steel, carbon), strip length, and strip width. For each specimen the deformation law (bond strength vs. total slip) up to maximum strength and elongation at failure, was recorded. Tested materials were classified according to their debonding strength and deformation capacity. Useful conclusions were drawn with respect to the influence of reinforced polymers length and width on the strength and deformation capacity. Analytical models available in the literature were applied, and the one proposed by Chen and Teng was found to better match the experimental measurements.
\end{abstract}

\section{INTRODUCTION}

The mechanisms involved in the strengthening of reinforced concrete $(\mathrm{R} / \mathrm{C})$ structural elements with externally applied composite materials, such as FRPs and SRPs can be described through constitutive laws for these materials, as well as for their interaction with concrete.

Steel Reinforced Polymers (SRPs), which are the key focus of this study) are 'third millennium materials', since first results were reported during the last five years. In tests performed by Wobbe et al., 2004, [1], the flexural mechanism of three R/C beams was strengthened by the use of SRP and Steel Reinforced Grout (SRG). The increase in flexural strength varied from 40 to $70 \%$. Strengthened specimens failed in a brittle way due to concrete cover delamination at the anchor zones of SRP and SRG. The deformation capacity at the midspan of strengthened specimens, compared with the corresponding deformation of the control specimen, was significantly reduced.

At tests performed by Prota et al., 2004, 2006, [2-4], eleven R/C beams were tested. Two beams were tested unstrengthened, and nine beams were tested strengthened by FRP, SRP and SRG. These materials were applied in one, two or three plies. Two of the beams strengthened with steel tape and cementitious grout were mechanically anchored with nail anchors. It was concluded that strength increases provided by SRP bonded with cementitious grout were smaller than those obtained using epoxy. CFRP was more effective than epoxy-bonded SRP in terms of strength; the trend was inverted in terms of ultimate deflections. Strains

*Address correspondence to this author at the Civil Engineering Department, Aristotle University of Thessaloniki, 54124 Thessaloniki, Greece; E-mail: ajkap@civil.auth.gr recorded indicated that interface behaviour and its influence on failure modes is mainly dependent on the matrix rather than on the type of fibre (steel versus carbon). Also in published work by the same team [5], the experimental findings were compared with the predictions provided by proposed analytical models and good agreement was obtained.

In the work presented by Casadei et al., 2005, [6-8] the flexural performance of Prestressed Concrete (PC) double-T beams, upgraded in the positive moment region with SRP composite materials, is investigated; this is the first study where this material has been applied in the field. These beams were part of the structural system of a two-storey parking garage. Three beams were tested: a control beam, a beam strengthened with one ply of SRP and a third beam strengthened with two plies of SRP anchored at both ends with SRP U-wraps. Results showed that SRP can significantly improve flexural capacity and enhance ductility. Preliminary analytical work showed that the same approach used for externally bonded FRP can be satisfactorily used for SRP.

Huang et al., 2005, [9] evaluated experimentally the properties of SRP and compared these properties to micromechanical equations to determine if such equations are suitable for the prediction of material constants. The effectiveness of SRP and CFRP was evaluated on existing structures, while SRG performance was studied on laboratory-prepared large-scale R/C beams. It was concluded that SRP and SRG can be easily and economically manufactured, offering great potential for strengthening of concrete bridges and buildings. These materials can be easily and reliably bonded to concrete structures. The properties of SRP can be accurately predicted by mechanics of materials, using micromechanics models. The ultimate strength of a reinforced concrete flexural member obtained by saw-cutting an existing parking garage floor 
and tested in-situ, was more than doubled when it was strengthened with SRP and CFRP composites. Also, in laboratory tests, the strength increase in a $\mathrm{R} / \mathrm{C}$ beam strengthened with SRP and SRG was higher by 30 and $20 \%$, respectively.

Matana et al., 2005, [10,11] examined the bond performance between SRP/SRG and concrete substrate using direct shear testing. The variables included type of SRP/SRG, concrete surface roughness and bonded length. SRP specimens experienced concrete shearing failure with considerable damage of the concrete, while SRG specimens experienced failure in the grout layer. Effective bond length was calculated for SRP specimens and was found to be about $127 \mathrm{~mm}$, which is somewhat larger than in FRP specimens, where it is reported to be about $102 \mathrm{~mm}$. For SRG, the effective bond length is larger than $305 \mathrm{~mm}$.

The mechanical properties of SRP were evaluated and their application in flexural strengthening of R/C beams was investigated by Kim et al., 2005, [12]. Six beams were tested in three-point bending. Test parameters included variation of the width of SRP sheets and the use of SRP U-wraps to prevent premature failure caused by delamination of the longitudinal sheet. Significant increase in flexural capacity, up to $53 \%$, and pseudo-ductile failure modes were observed in SRP-strengthened beams. Failure was governed primarily by concrete cover delamination at the ends of SRP sheets or concrete crushing. The U-wraps improved flexural stiffness by means of controlling diagonal cracking and providing anchorages to the longitudinal SRP sheets. An analytical model was proposed for predicting the nominal flexural strength of SRP-strengthened beams.

Figeys et al., 2005, [13] investigated the strengthening of R/C structures using SRPs. First, the behaviour of the bonded connection (on concrete) with SRP was examined. Nonlinear fracture mechanics was applied to model and describe the shear-slip behaviour of the bonded connection. Some model parameters, specific to the new material, were determined by means of direct shear tests. Then, five beams were tested in four-point bending. One beam was unstrengthened, three beams were strengthened with one layer of SRP and the last beam was strengthened with two SRP layers. Shear slip tests demonstrated that SRP-strengthened members were stronger and stiffer than CFRP-strengthened ones. Materialrelated parameters for SRP, to be used for design purposes, were proposed, and the need to consider delamination failure modes in strengthened beams was pointed out.

An experimental study has been conducted by Thermou et al., 2006, [14] to investigate the efficiency of GFRP (Glass FRP), CFRP and SRP in upgrading the seismic behaviour of substandard R/C prismatic members. Sixteen specimens, representative of a typical building column, were tested. After the initial tests, specimens were repaired/ strengthened with the aforementioned materials and then retested. The potential of SRP as a strengthening/repair material emerged from the experimental evidence. In most cases retrofitted specimens attained increased strength and deformation capacity with respect to their initial properties. Comparison with the performance enhancement imparted by the FRP jackets (glass and carbon) demonstrated the higher efficiency of SRPs.
The present study reports on the initial phases of a programme focussing on the behaviour of concrete beams strengthened with reinforced polymers. Tensile tests on the strengthening materials with and without epoxy resin were first carried out. These aimed to determine the composite material modulus of elasticity and fracture elongation, both of which are critical parameters for describing the response of structural elements strengthened using these materials. Results from these tests are presented in the next section. The section following the next describes the experimental set-up and test results from the second phase of the experimental programme. More specifically, tension tests were carried out involving SRP strips bonded on concrete prisms. For comparison purposes, similar tests were made involving CFRP strips. For each specimen the deformation law (bond strength vs. total slip) up to maximum strength and elongation at failure, was recorded. The experimentally measured bond strengths were subsequently estimated using analytical models available in the literature and results are discussed in the last section of the paper.

\section{TESTS FOR ESTIMATING MATERIAL PROPER- TIES}

SRP and CFRP strips were used here as strengthening materials. SRP strips were of two types, SRP 3X2-23-12 and SRP 12X-23-12; the chords that make up the SRP strips are shown in Fig. (1), while more details regarding these materials can be found in www.hardwirellc.com/products.html. The SRP strips were tested during the first series of tests (Mitolidis et al. 2006) [15], in order to determine their modulus of elasticity and elongation capacity. From these tests it was found that for the SRP3X2-23-12 strip, Young's modulus is $78348 \mathrm{MPa}$ and fracture elongation is $1.56 \%$ (SRP after the application of the resin); for SRP 12X-23-12 the Young's modulus was $67318 \mathrm{MPa}$ and fracture elongation 1.61\% (SRP after the application of the resin). For the carbon fibre strip (CarboDur S512) used in the tests reported here, the properties specified by the manufacturer were a Young's modulus of $160000 \mathrm{MPa}$ and a fracture elongation of $1.70 \%$.

\section{$12 \times$ Cord}

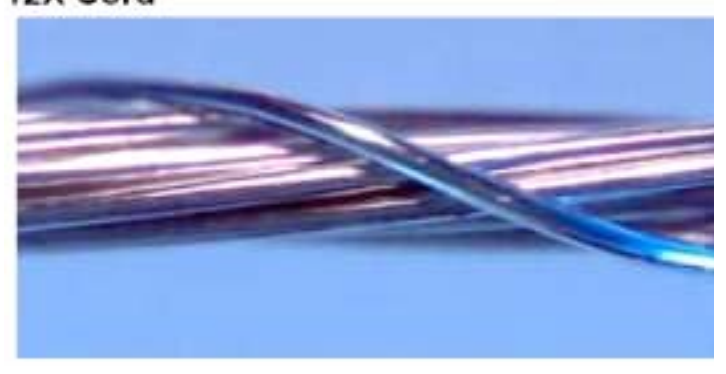

\section{$3 \times 2$ Cord}

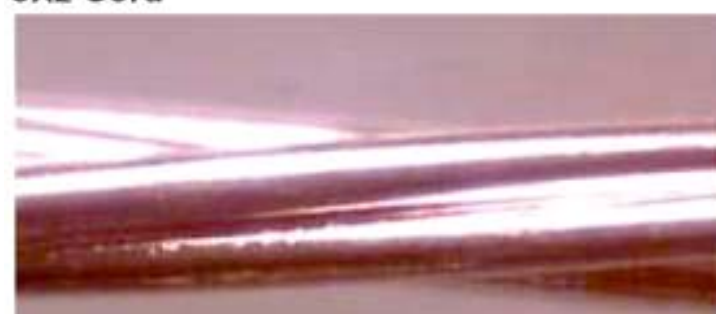

Fig. (1). Photos of the SRP cords used in present study. 


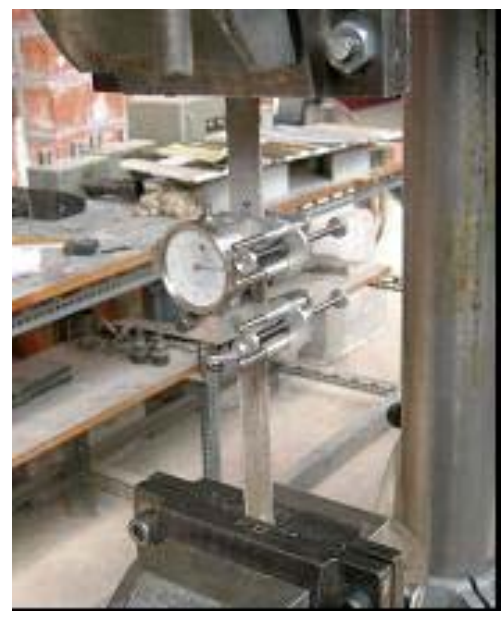

Fig. (2). Photo during tensile rest.

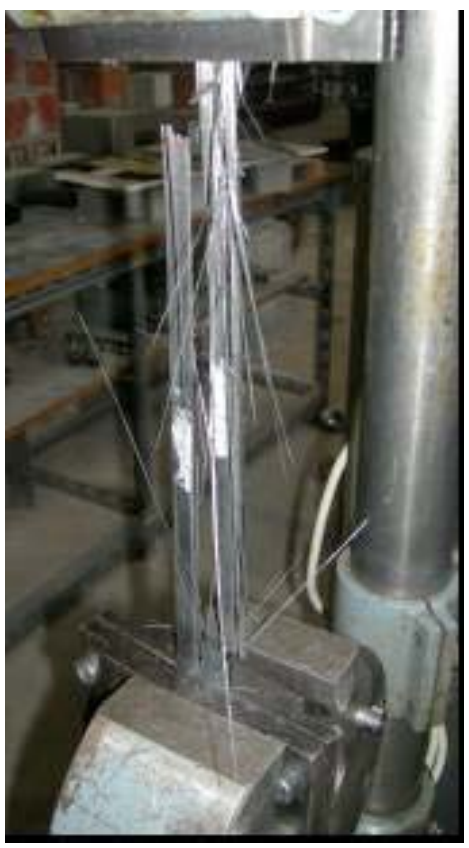

Fig. (3). CFRP specimen after tensile test.

The specifications adopted in ASTM Standard D 3039M were applied in the tests. These specifications cover testing of fibre polymers after the application and hardening of the epoxy resin. A key provision in this Standard is that the width of the specimen to be tested in tension should be significantly smaller than the length of the specimen. This specification aims to minimize the undesirable influence that any eccentricity and unequal gripping force at the ends of the specimen, may have on the failure mode and the measurements. The possibility of unequal gripping force is very high due to the fact that resin layers at the ends of the specimen are not of uniform thickness. It is very difficult to achieve perfectly parallel surfaces on the two sides of the specimen. For this reason some treatment is necessary at the end of the specimens before each test; it is recommended to file the ends of the specimens, on both sides, during the first hours after the application of the resin. These recommendations are meant to apply only in the case of laboratory tests and not during the use of SRPs for strengthening and/or repair in real structures. When specimens are installed in the tension machine, conical wedges should be used for firmly holding the two ends of the specimen. This mechanism does not always prevent slip at the ends of the specimen. Hence, the use of prestressed bolts is recommended in order to achieve firm holding at the ends of the tension specimen.
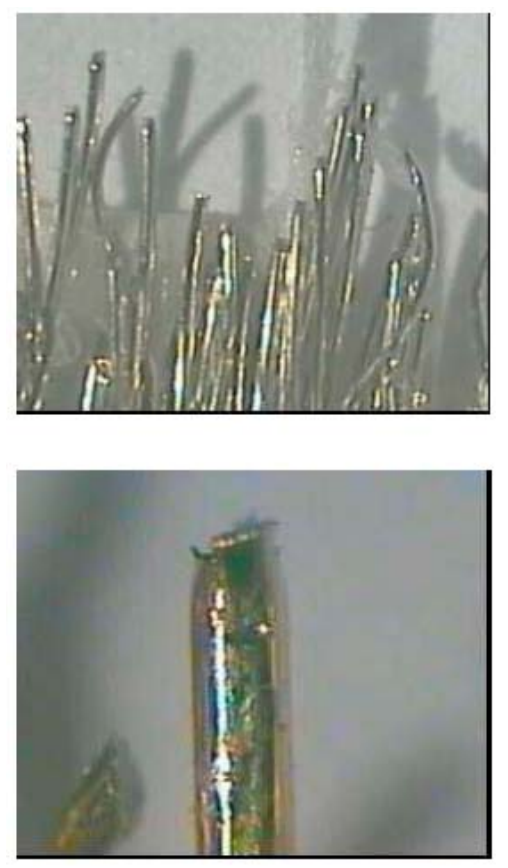

Fig. (4). Details of SRP cords and wire after tensile testing.

The cross-section of the specimens tested in the present study was constant without any additional layer of polymer. This was decided in order to avoid possible reduced anchorage conditions at the end of the specimen.

Although the elongation of the specimen was measured directly by the tension machine, this measurement was not taken into account since this value was affected by slip at the ends of the specimen. The elongation was measured by a purposely-placed instrument spanning between two points close to the half-length of the specimen. The distance between these two points was $50 \mathrm{~mm}$ and the elongation was measured with a tolerance of $1 / 200 \mathrm{~mm}$. Photographs from tensile tests are given in Figs. (2-4).

Results for SRP and CFRP specimens, tested as shown in Figs. (2 and 3), are presented in a comparative way in Figs. (5a-c). Table 1 gives the values of the final strength, total elongation, the corresponding mean values, and the manufacturer values for the materials that were tested. The variability in the measured values for each material is relatively small in the case of SRP strips, and higher in the case of CFRP strips. It is noted that the reported stresses for the tested specimens are based on the final cross-section of the laminate (SRP strip and hardened resin). Measured values of effective modulus are very similar to manufacturer values in the case of SRP strips and 30\% higher in the case of CFRP strips, while measured stresses at fracture is slightly lower (less than 7\%) than the manufacturer values for SPRs and about $14 \%$ lower for CFRPs. 

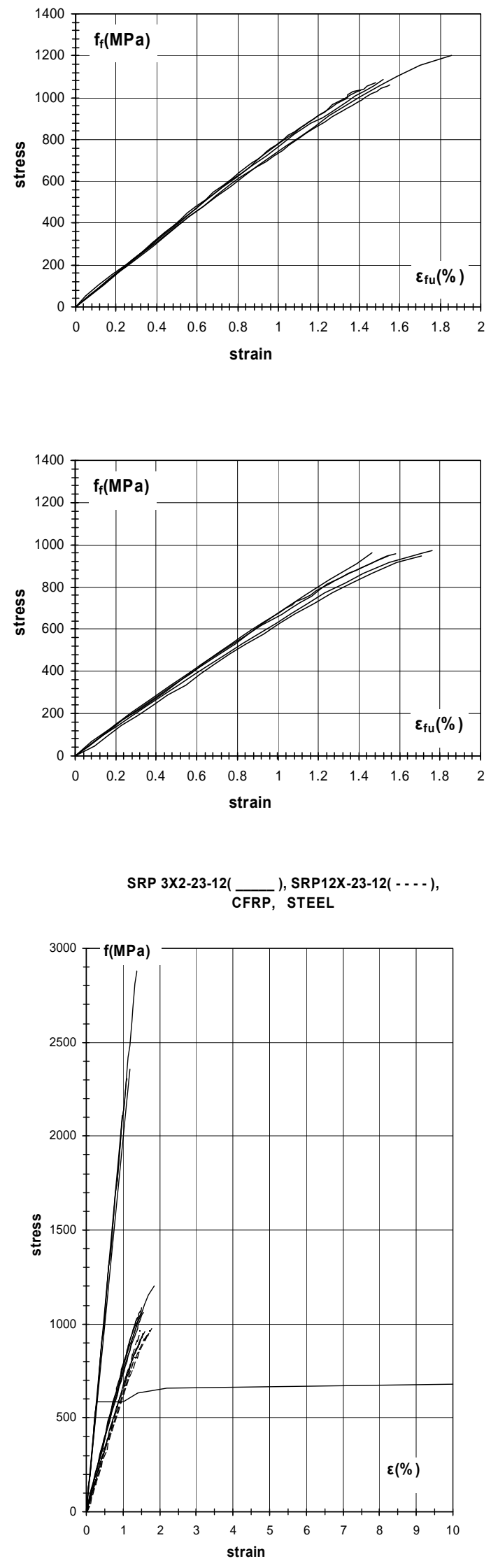

Fig. (5). Stress - Strain diagrams for a)SRP3X2, b)SRP12X and c) for CFRP, SRP and Steel Reinforcement.

\section{BOND TESTS}

\section{Properties of Concrete Used}

The choice of the concrete mix for the bond test specimens was made with a view to reproducing concrete with strength similar to the current strength (accounting for time effects) of concrete in elements that were cast a few decades ago. This was done since older concrete structures of the period from 1960 to 1980 are typically the ones to be strengthened by the materials tested whenever the need for a strengthening intervention arises. The following concrete mix was used for the construction of concrete prisms.

- Common Portland cement I42.5 $345 \mathrm{~kg} / \mathrm{m}^{3}$

- Water $207 \mathrm{~kg} / \mathrm{m}^{3}$

- Crushed sand $756 \mathrm{~kg} / \mathrm{m}^{3}$

- Fine aggregate $378 \mathrm{~kg} / \mathrm{m}^{3}$

- Coarse aggregate $756 \mathrm{~kg} / \mathrm{m}^{3}$

A common value of compressive strength for concrete used in Greece for multistorey building construction (usually 5 to 8 floors) during the period 1960 to 1980 was $225 \mathrm{~kg} / \mathrm{cm}^{2}$ (cube strength at the $28^{\text {th }}$ day after casting); note that in the following, concrete strength is first given in $\mathrm{kg} / \mathrm{cm}^{2}$ units, as done in the aforementioned period, and is subsequently converted to $\mathrm{MPa}$, the curently used SI unit. The average compressive cylinder strength for the concrete used was 224.3 $\mathrm{kg} / \mathrm{cm}^{2}$. The standard deviation for these specimens was $\sigma_{\mathrm{n}}=$ $12.4 \mathrm{~kg} / \mathrm{cm}^{2}$ hence the corresponding characteristic strength $(5 \%$ fractile $)$ is $\mathrm{f}_{\mathrm{ck}}=\mathrm{f}_{\mathrm{cm}}-1.64 \times \sigma_{\mathrm{n}}=224.3-1.64 \times 12.4(\mathrm{~kg} /$ $\left.\mathrm{cm}^{2}\right)=204.0 \mathrm{~kg} / \mathrm{cm}^{2}$ or $20.0 \mathrm{MPa}$, and the corresponding cube strength $20 \mathrm{MPa} \times 1.21=24.2 \mathrm{MPa}$. This concrete grade is similar to the $\mathrm{C} 20 / 25$ class of the current Concrete Code. The average compressive cylinder strength of 224. $3 \mathrm{~kg} / \mathrm{cm}^{2}$ corresponds to a $269.2 \mathrm{~kg} / \mathrm{cm}^{2}$ compressive cube strength $(20 \mathrm{~cm}$ cubes $)$, which is reasonable for a 30 to 40 year old concrete of the type described previously. The average tensile strength from three specimens was found to be $\mathrm{f}_{\mathrm{ctm}}=2.4 \mathrm{MPa}$. Using the relationship of the Concrete Code for estimating tensile strengths from the corresponding (mean) compressive strength, the tensile strength is $\mathrm{f}_{\mathrm{ctm}}=0.30 \mathrm{f}_{\mathrm{ck}}{ }^{2 / 3}$ $=0.30 \times(20.0)^{2 / 3}=2.2 \mathrm{MPa}$, which is close to the previous value.

\section{TEST DESCRIPTION AND RESULTS}

In order to evaluate the bond strength of the considered strengthening materials, a number of specimens were tested; concrete prisms were used for this purpose. The surface of these prisms was roughened before the bonding of the SRP and CFRP strips with the concrete substrate. On the one end the applied materials were surrounded by two layers of CFRP in order to assure that the other end of the specimen, to which the total slip was measured using an LVDT, will fail first. Elongations were filmed by recording the indications of the voltmeters that were connected to the LVDT's, as well as the stress (force) indications. Based on these indications of the instruments, diagrams of bond strength versus total slip were drawn for all specimens. Typical specimens and the test set-up are presented in Figs. $(6,7)$. In the same figure representative drawings of the tested specimens are also given. Provisions of the Japanese Standard JSCE-E 543-2000, [16], were taken into account for the design of the 
Table 1. Measured Properties of the Tested Materials

\begin{tabular}{|c|c|c|c|c|c|}
\hline \multirow{2}{*}{ Specimens } & \multirow{2}{*}{ Material Type } & Cross Section & Effective Modulus & Fracture Stress & Fracture Strain \\
\hline & & $(\mathbf{m m})$ & MPa & MPa & $(\%)$ \\
\hline $\mathrm{I} 21$ & SRP 3X2-23-12 & $15.5 \times 1.23$ & 80100 & 1088.2 & 1.52 \\
\hline $\mathrm{I} 12$ & SRP 3X2-23-12 & $28.7 \times 1.23$ & 79340 & 1069.2 & 1.48 \\
\hline $\mathrm{I} 13$ & SRP 3X2-23-12 & $49.6 \times 1.23$ & 80020 & 1035.2 & 1.41 \\
\hline I11 & SRP 12X-23-12 & $16.6 \times 1.23$ & 62750 & 948.5 & 1.71 \\
\hline $\mathrm{I} 21$ & SRP $12 X-23-12$ & $16.6 \times 1.23$ & 65160 & 972.5 & 1.76 \\
\hline $\mathrm{I} 12$ & SRP $12 X-23-12$ & $28.5 \times 1.23$ & 67810 & 960.5 & 1.46 \\
\hline Manuf. Values & SRP $3 X 2-23-12$ & & 77900 & 1171.1 & \\
\hline Mean Values & SRP $12 X-23-12$ & & 67318 & 957.3 & 1.61 \\
\hline Manuf. Values & SRP 12X-23-12 & & 67600 & 951.0 & \\
\hline CFRP (Mean Values) & CarboDur S512 & $25.0 \times 1.2$ & 208047 & 2413.3 & 1.18 \\
\hline Manuf. Values (min) & CarboDur S512 & & 160000 & 2800.0 & 1.70 \\
\hline
\end{tabular}
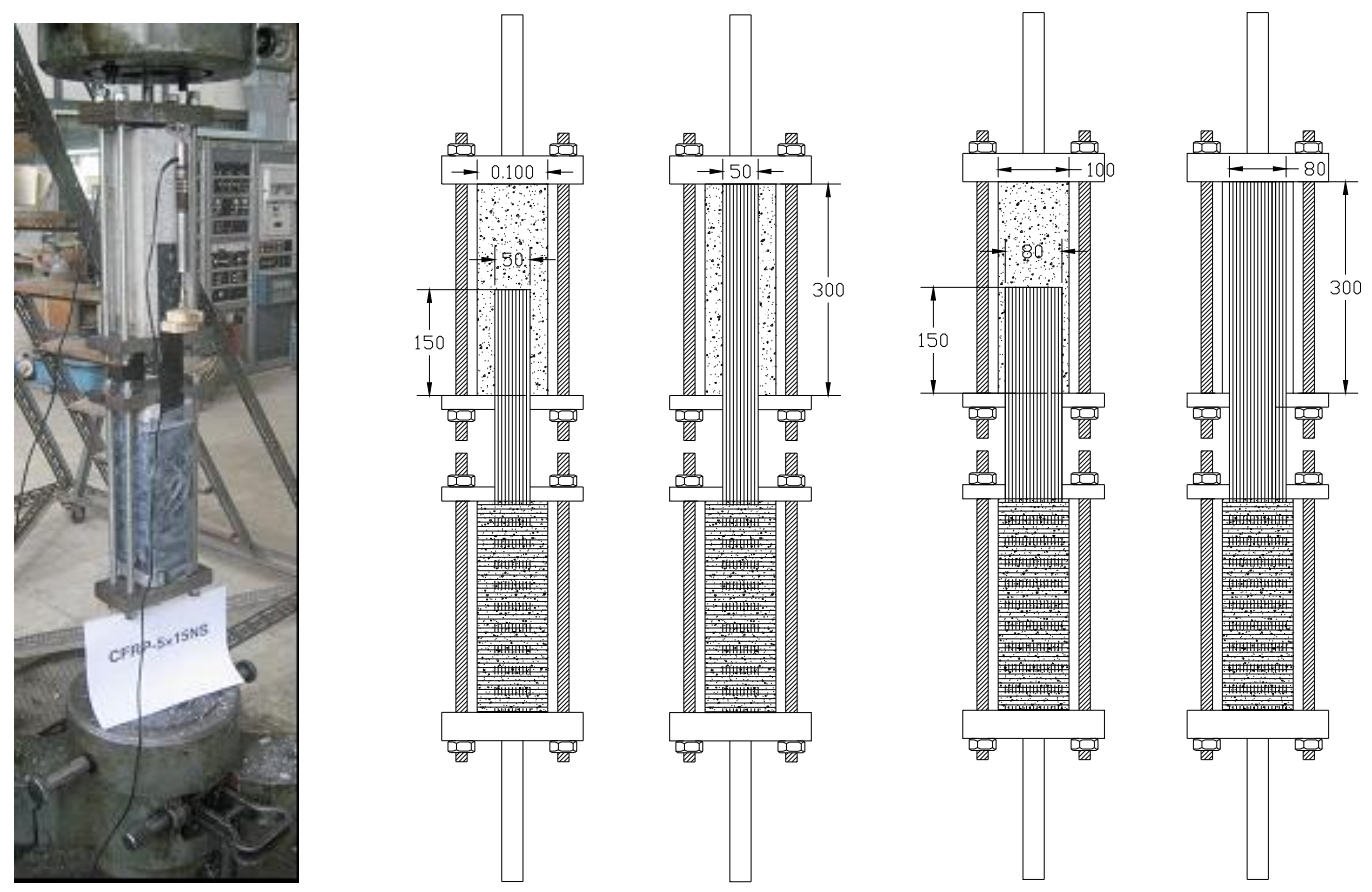

Fig. (6). Specimen ready for testing, and configurations of representative specimens.

specimens, except that an open gap was provided between concrete prisms for better controlling construction faults and tolerances. Table 2 describes the specimens on which bond tests were carried out, and presents the most important results.
In Figs. (8-11), diagrams of total force $\left(\mathrm{P}_{\text {tot }}\right)$ vs. total slip $\left(s_{\text {tot,u }}\right)$ are given for the tested specimens. They are appropriately grouped according to the width and length of the composite material strips. In all tests an inelastic branch of the P-s curve was recorded during the activation of the debond- 


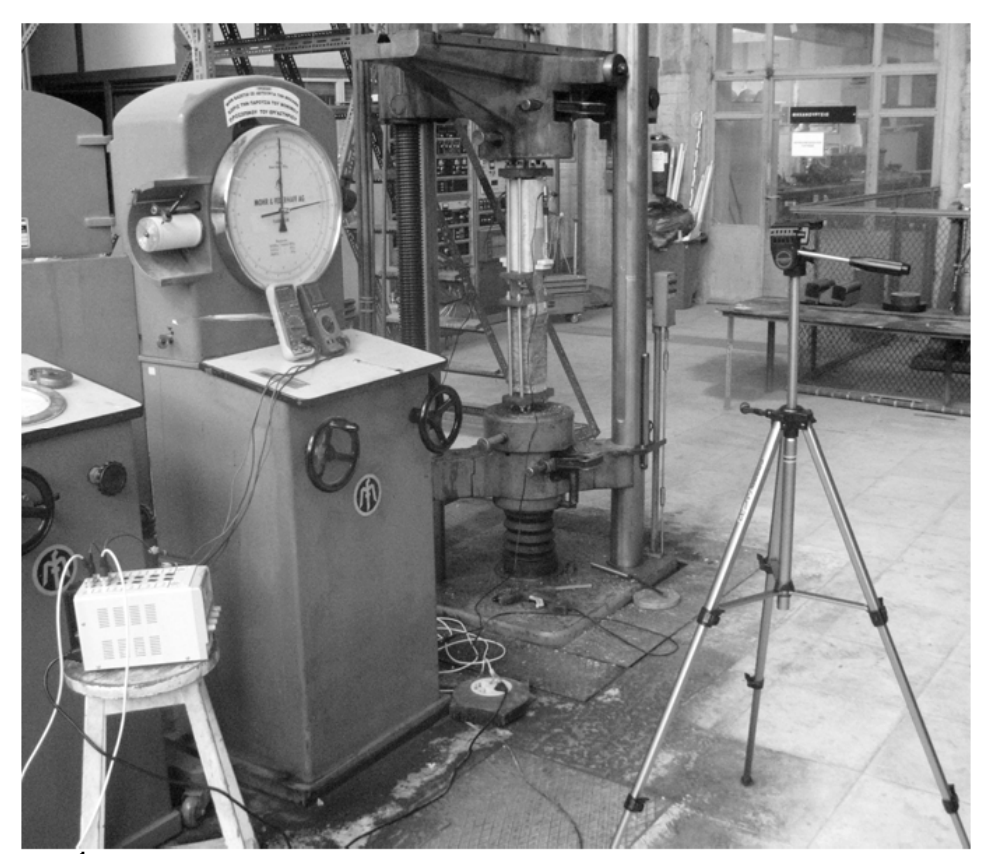

Fig. (7). Experimental set - up.

Table 2. Specimen Data and Key Results from Bond Tests

\begin{tabular}{|c|c|c|c|c|c|}
\hline \multirow{2}{*}{ Specimen } & \multirow{2}{*}{ Concrete Grade } & $\mathbf{t}_{\mathrm{f}} \times \mathbf{b}_{\mathrm{f}} \times \mathbf{L}$ & \multirow{2}{*}{ Type of Strip } & \multirow{2}{*}{$\begin{array}{c}0.5 P_{\text {tot }} \\
k N\end{array}$} & \multirow{2}{*}{$\begin{array}{c}\mathbf{S}_{\text {tot }}{ }^{*} / \mathbf{s}_{\text {tot,u }} \\
\mathbf{m m}\end{array}$} \\
\hline & & $\mathbf{m m}$ & & & \\
\hline CFRP-5X30NS & $\mathrm{C} 20 / 25$ & $1.20 \times 50 \times 300$ & CFRP & 18.5 & $0.50 / 0.70$ \\
\hline SRP12-5X15NS & $\mathrm{C} 20 / 25$ & $1.23 \times 50 \times 150$ & SRP12X & 13.7 & $1.09 / 1.25$ \\
\hline SRP12-8X15NS & $\mathrm{C} 20 / 25$ & $1.23 \times 80 \times 150$ & SRP12X & 19.0 & $0.55 /-$ \\
\hline SRP12-8X30NS & $\mathrm{C} 20 / 25$ & $1.23 \times 80 \times 300$ & SRP12X & 21.0 & $0.58 / 0.99$ \\
\hline SRP3X2-5X15NS & $\mathrm{C} 20 / 25$ & $1.23 \times 50 \times 150$ & SRP3X2 & 15.0 & $0.45 / 0.56$ \\
\hline SRP3X2-5X30NS & $\mathrm{C} 20 / 25$ & $1.23 \times 50 \times 300$ & SRP3X2 & 14.0 & $-/ 0.60$ \\
\hline
\end{tabular}

${ }^{*} \mathrm{~s}_{\mathrm{tot}}$ : measured displacement between the outer points of the bonded lengths.

ing mechanism for the reinforced polymers used. A discussion of the effects of the parameters that varied among the specimens is provided in the following.

Polymer type: Subject to the limitation that only two CFRP strips were tested, it was found that their bond strength was higher than that of SRPs. This is explained by considering the significantly higher elastic modulus of CFRP than the elastic modulus of SRP (see equations 2, 5, 6 in the next section). More specifically, the average debonding strength for CFRP was $37.4 \mathrm{kN}$ while for SRP12 it was 27.7 $\mathrm{kN}$, and for SRP3X2 $29.0 \mathrm{kN}$. The average debonding strength for SRP strips was $28.4 \mathrm{kN}$, taking into account all specimens with $b_{f}=50 \mathrm{~mm}$, which is $76 \%$ of the debonding strength of CFRP.

Composite material width: The composite material width was found to clearly affect the debonding strength, as expected. For specimens with $80 \mathrm{~mm}$ of composite material width the average debonding strength was found to be 41 . $13 \mathrm{kN}$, while for specimens with $50 \mathrm{~mm}$ of composite material width the average debonding strength was $28.35 \mathrm{kN}$ (SRP12: $27.7 \mathrm{kN}, \mathrm{SRP} 3 \mathrm{X} 2: 29.0 \mathrm{kN}$ ). Interestingly, the ratio of the ultimate loads is not exactly proportional to the width of the strips, which is an indication of the complex bond stress distribution along the strips. 


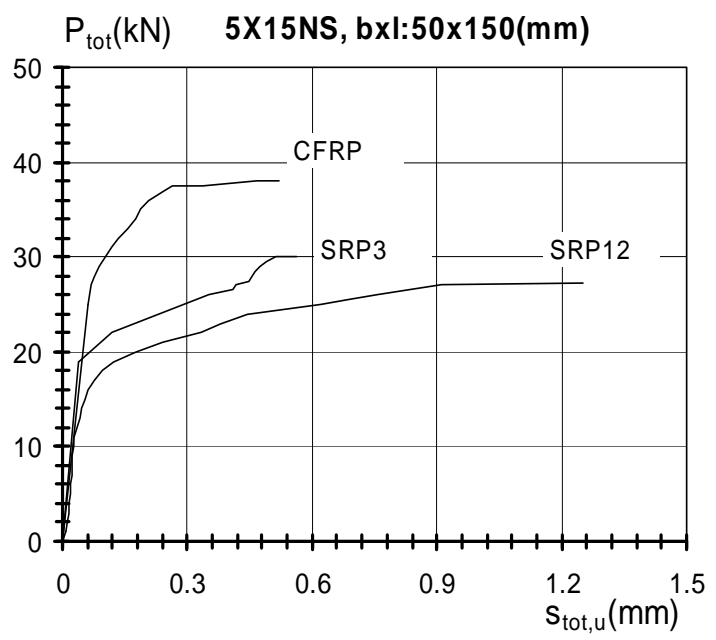

Fig. (8). Diagram of total force vs. total bond slip for $5 \times 15$ specimens.

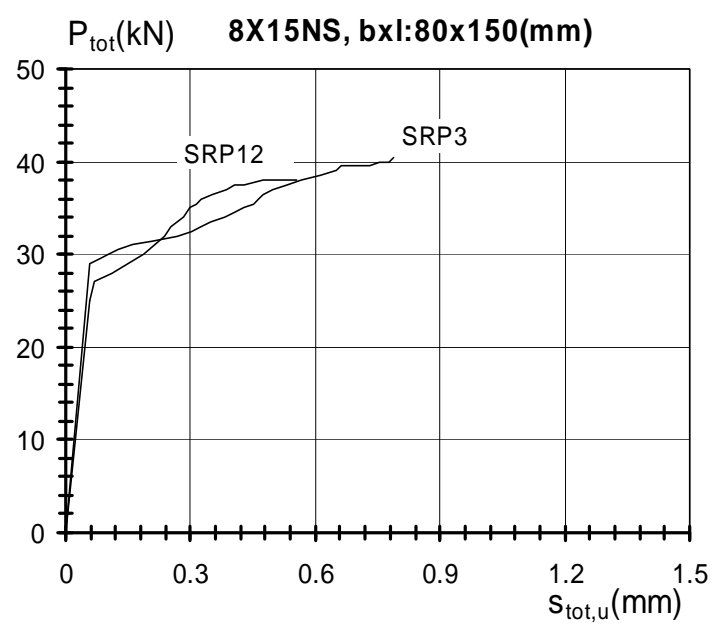

Fig. (9). Diagram of total force vs. total bond slip for $8 \times 15$ specimens.

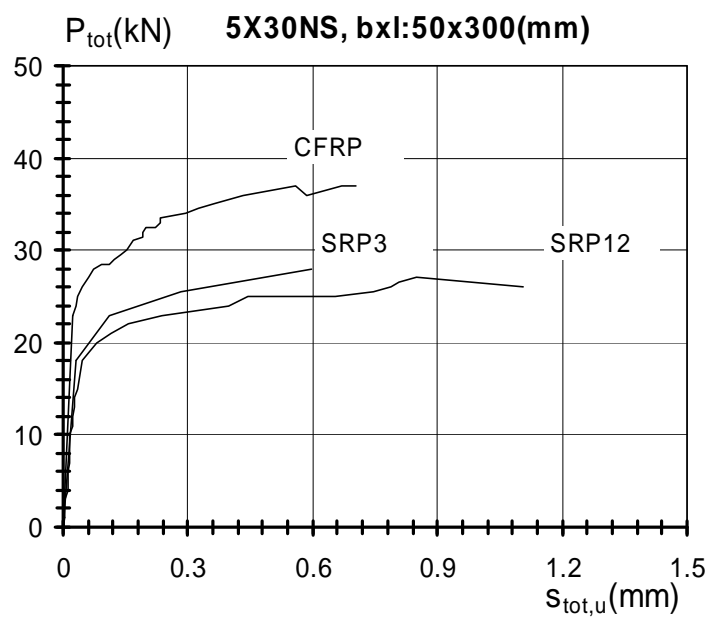

Fig. (10). Diagram of total force vs. total bond slip for $5 \times 30$ specimens.

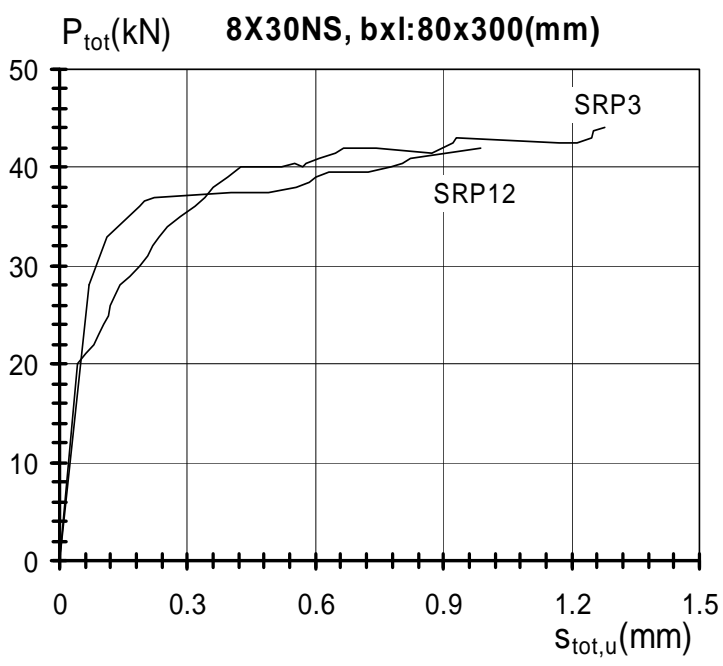

Fig. (11). Diagram of total force vs. total bond slip for $8 \times 30$ specimens.

Composite material length: The different length of the composite material $(300 \mathrm{~mm}$ and $150 \mathrm{~mm})$ was not found to affect significantly the debonding strength. For specimens with $300 \mathrm{~mm}$ long strips the average debonding strength was measured at $34.4 \mathrm{kN}$, while for specimens with $150 \mathrm{~mm}$ long strips the average debonding strength was $33.3 \mathrm{kN}$. This shows that for each case of composite material used, the effective anchorage length was less than $150 \mathrm{~mm}$, a value that is in agreement with the existing literature.

Debonding Slip: For the three types of composite materials that were tested, clear differences were observed in the value of slip at failure. For CFRP the average slip at failure was $0.52 \mathrm{~mm}$, for SRP12 the average slip at failure was $0.95 \mathrm{~mm}$ and for SRP3X2 the respective value was $0.71 \mathrm{~mm}$. These differences can be explained by the differences in the modulus of elasticity of CFRP and SRP12, SRP3X2, which were measured.

\section{PREDICTION OF BOND STRENGTH USING CUR- RENTLY AVAILABLE MODELS}

To select appropriate models for estimating bond strength, recourse was made to the recent work of Toutanji et al. (2007), [17]. In this work, analytical models for the estimation of bond strength, available in the literature, were evaluated on the basis of 351 bond tests performed in the past, and it was found that the formulas proposed by Chen \& Teng (2001), Neubauer \& Rostasy (1997), Yang et al. (2001) and Yuan \& Wu (1999) (full references for these models are given in [17]) are generally appropriate for calculating the bond strength. The values of bond strength measured in the tests reported herein were then estimated using the aforementioned four analytical models. These models involve the product $b_{f} \cdot L_{e}$ and a term representing an equivalent bond stress. The symbols used in equations (1) to (6) below are explained in the Notation section at the end of the paper.

Chen and Teng (2001)

$P_{u}=0.427 \beta_{p} \beta_{L} \sqrt{f_{c}^{\prime}} b_{f} L_{e}$ 


$$
\begin{aligned}
& L_{e}=\sqrt{\frac{E_{f} t_{f}}{\sqrt{f_{c}}}}, \beta_{p}=\sqrt{\frac{2-b_{f} / b_{c}}{1+b_{f} / b_{c}}}, \\
& \beta_{\mathrm{L}}=1 \text { if } \mathrm{L} \geq \mathrm{L}_{\mathrm{e}}, \beta_{L}=\sin \frac{\pi L}{2 L_{e}} \text { if } \mathrm{L}<\mathrm{L}_{\mathrm{e}}
\end{aligned}
$$

Neubauer and Rostasy (1997)

$$
\begin{aligned}
& P_{u}=0.64 k_{f} b_{f} \sqrt{E_{f} t_{f} f_{c t m}} \quad, \text { if } \mathrm{L} \geq \mathrm{L}_{\mathrm{e}} \\
& P_{u}=0.64 k_{f} b_{f} \sqrt{E_{f} t_{f} f_{c t m}} \frac{L}{L_{e}}\left(2-\frac{L}{L_{e}}\right), \text { if } \mathrm{L}<\mathrm{L}_{\mathrm{e}}
\end{aligned}
$$$$
L_{e}=\sqrt{\frac{E_{f} t_{f}}{2 f_{c t m}}}, k_{f}=\sqrt{\frac{1.125\left(2-\frac{b_{f}}{b}\right)}{1+\frac{b_{f}}{400}}} \geq 1
$$

Yang et al. (2001)

$$
\begin{aligned}
& P_{u}=\left(0.5+0.08 \sqrt{\frac{E_{f} t_{f}}{100 f_{c t}}}\right) L_{e} b_{f}\left(0.5 f_{c t}\right) \\
& \mathrm{L}_{\mathrm{e}}=100 \mathrm{~mm}
\end{aligned}
$$

Yuan and Wu (1999)

$$
P_{u}=\sqrt{\frac{2 E_{f} t_{f} G_{f}}{1+\alpha_{Y}}} \cdot b_{f}, \alpha_{Y}=\frac{b_{f} E_{f} t_{f}}{b_{c} E_{c} t_{c}}
$$

In Equation (6) the elastic modulus of concrete that is used is $29000 \mathrm{MPa}$. In Fig. (12) are presented comparative diagrams for the experimentally measured bond strengths versus the analytically calculated values according to equations (1) to (6). In these diagrams six more specimens (not reported herein) are included, in which high strength concrete was used.

For the four selected models the bond strength of the specimens of the present paper is calculated, and results are reported in Table 3. It is clear from this table and from the comparative diagrams (Fig. 12), that the selected numerical
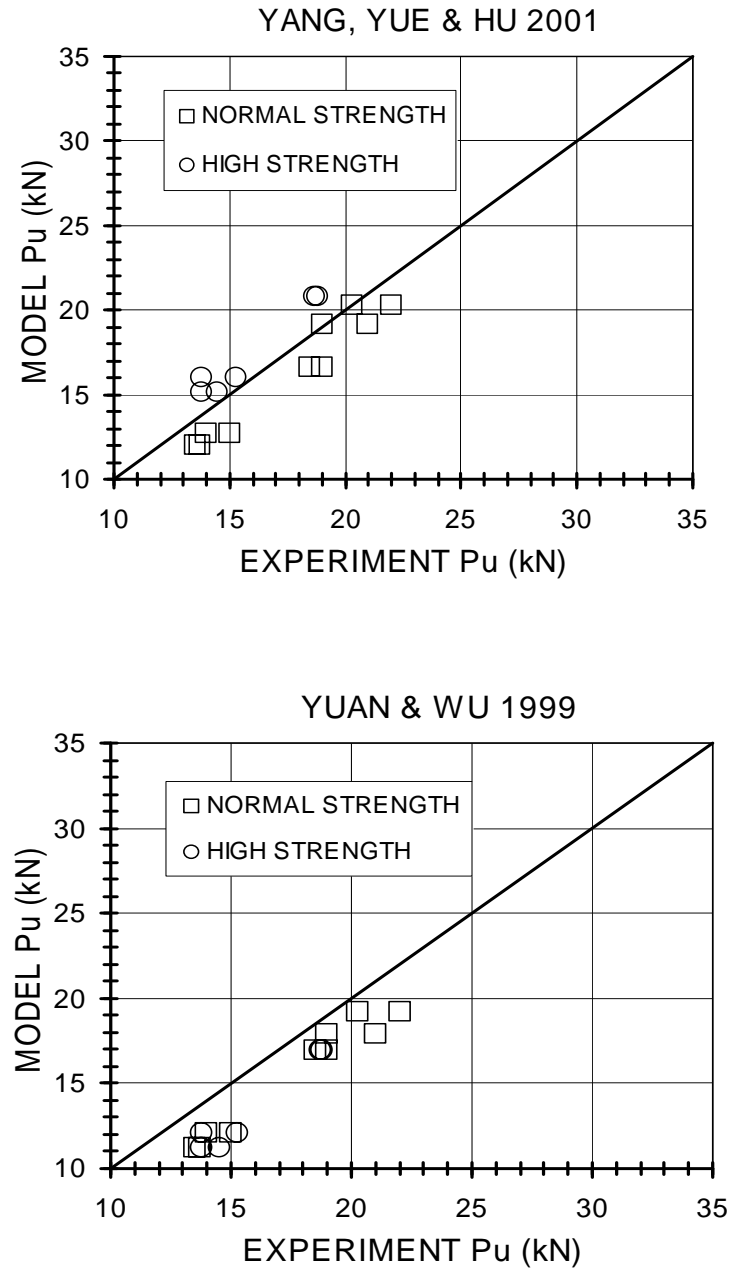

Fig. (12). Comparisons of predicted and measured values of bond strength. 
Table 3. Bond Strength Predicted by Analytical Models and Corresponding Values from Tests

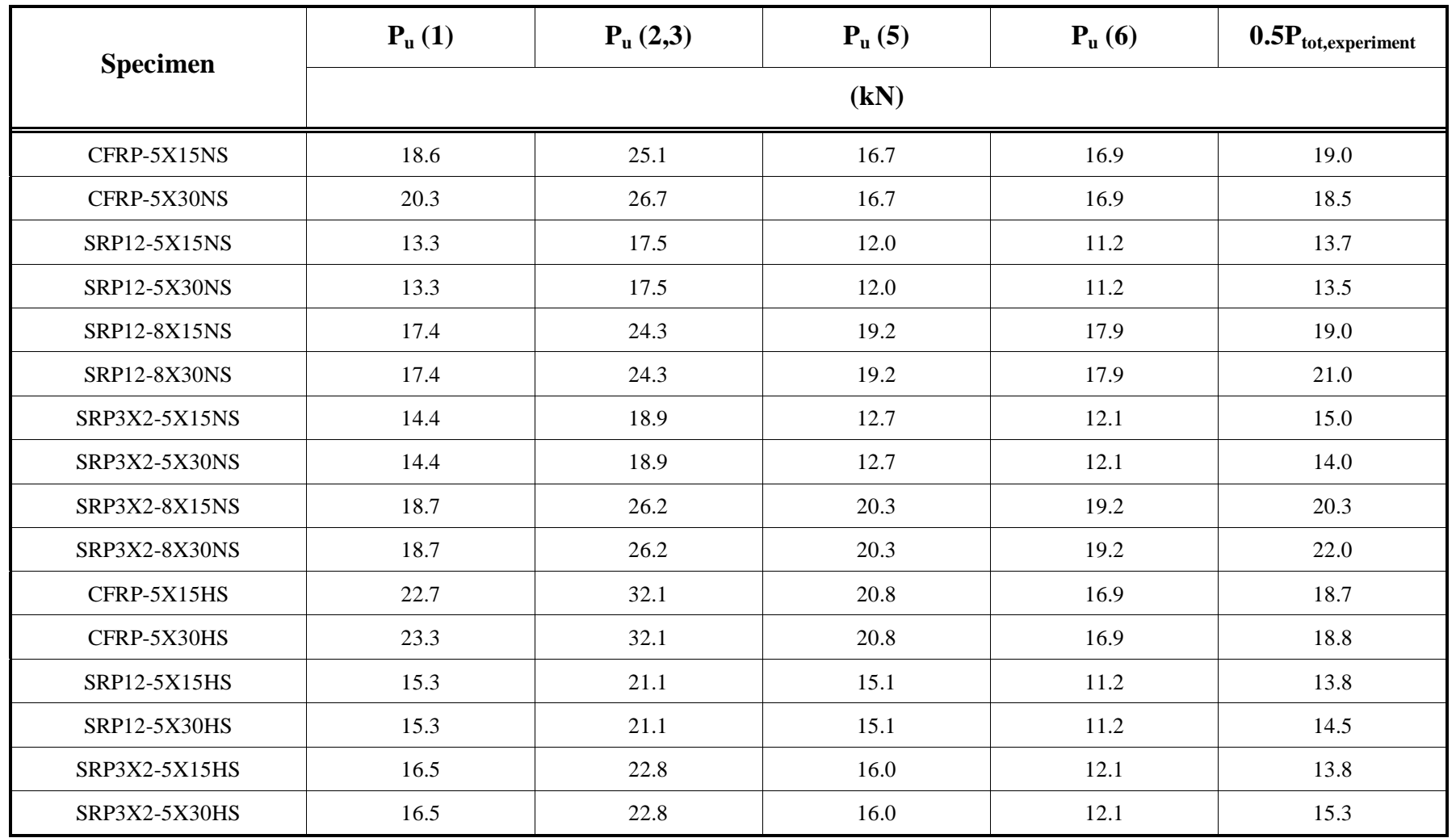

models generally predict satisfactorily the bond strengths that were measured experimentally. In particular the model proposed by Chen and Teng (2001) gives a satisfactory prediction for all types of composite materials tested herein.

\section{CONCLUSIONS}

The key conclusions from the present study are summarised in the following.

In tension specimens of polymer laminates the width should be significantly smaller than the length of the specimen. Stress at failure of SRP specimens was found to be lower than that of CFRP specimens, but higher than that of steel reinforcement. For SRP strips the stress - strain relationship includes a short inelastic branch, while CFRP strips are characterised by a linear elastic, stress - strain relationship up to failure. The fracture elongation was almost the same for the SRP and CFRP specimens that were tested. For the 3X2 type of SRP a higher modulus of elasticity and fracture stress was measured, compared to the corresponding values for the $12 \mathrm{X}$ type of SRP.

From the tests conducted on reinforced polymer strips bonded on concrete prisms, it was found that CFRP strips had a higher debonding strength than SRP strips; this conclusion is subject to the limitation that only 2 CFRP specimens were tested (as opposed to the 8 SRP specimnes). As expected, the width of the composite material strip was found to affect the debonding strength, however the ratio of the ultimate loads was not exactly proportional to the width of the strips, which is an indication of the complex bond stress distribution. The different length of strips $(300 \mathrm{~mm}$ and

$150 \mathrm{~mm}$ ), being always larger than the effective anchorage length, was not found to affect the debonding strength.

The three types of composite materials tested showed clear differences in the slip for which failure due to debonding occurred. This is attributed to the different modulus of elasticity of the CFRP strips and of the two types of SRP strips.

Finally, the evaluation of bond strengths using various existing models, showed that these are generally appropriate, while the one proposed by Chen and Teng (2001) better predicts the experimental measurements for all types of composite materials addressed here.

\section{NOTATION}

$\mathrm{b}_{\mathrm{c}} \quad=$

$\mathrm{b}_{\mathrm{f}} \quad=$

$\mathrm{E}_{\mathrm{c}} \quad=$

$\mathrm{E}_{\mathrm{f}} \quad=$

$\mathrm{f}^{\prime}{ }_{\mathrm{c}} \quad=$

$\mathrm{f}_{\mathrm{cm}} \quad=$

$\mathrm{f}_{\mathrm{ctm}} \quad=$

$\mathrm{G}_{\mathrm{f}} \quad=$

$\mathrm{k}_{\mathrm{f}} \quad=$

$\mathrm{L} \quad=$
Width of concrete prisms

Width of polymer strips

Modulus of elasticity for the concrete

Modulus of elasticity for the polymers

Compressive strength for the concrete

Compressive strength for the concrete (cylinder specimens $30 \times 15 \mathrm{~cm}$, mean value) value)

Surface fracture energy

Geometry coefficient

Bond length 


$\begin{array}{lll}\mathrm{L}_{\mathrm{e}} & = & \text { Effective bond length } \\ \mathrm{P}_{\mathrm{u}} & = & \text { Bond strength } \\ \mathrm{t}_{\mathrm{c}} & = & \text { Thickness of concrete prism } \\ \mathrm{t}_{\mathrm{f}} & = & \text { Thickness of polymer strips } \\ \beta_{\mathrm{L}} & = & \text { Coefficient related to the bond length } \\ \beta_{\mathrm{p}} & = & \begin{array}{l}\text { Coefficient related to the polymer and con- } \\ \text { crete width }\end{array}\end{array}$

\section{ACKNOWLEDGEMENTS}

The research project, results of which are presented in this paper, is jointly funded by EU-European Social Fund, the Greek Ministry of Development-GSRT, and Sika - Hellas.

\section{REFERENCES}

[1] E. Wobbe, P. Silva, B.L. Barton, L.R. Dharani, V. Birman, A. Nanni, T. Alkhrdaji, J. Thomas and T. Tunis, "Flexural Capacity of R/C Beams Externally Bonded with SRP and SRG", in Proceedings of Society for the Advancement of Material and Process Engineering, Symposium, Long Beach, Ca, USA, 2004, pp. 20-27.

[2] A. Prota, G. Manfredi, A. Nanni, E. Cosenza and M. Pecce, "Flexural Strengthening of R/C Beams using Emerging Materials: Ultimate Behavior", in Proceedings of $2^{\text {nd }}$ International Conference on FRP Composites in Civil Engineering, CICE 2004, Adelaide, Australia, 2004, pp. 163-170.

[3] F. Ceroni, M. Pecce, A. Prota and G. Manfredi, "Flexural Strengthening of R/C Beams using Emerging Materials: Ultimate Behavior", Available at: http://www.hardwirellc.com/Downloads/ [Accessed Apr. 15, 2008].

[4] A. Prota, K.T. Yong, A. Nanni, M. Pecce and G. Manfredi, "Performance of Shallow R/C Beams with Externally Bonded SteelReinforced Polymer," ACI Structural Journal, vol. 103 (2), pp. 163$170,2006$.

[5] M. Pecce, F. Ceroni, A. Prota and G. Manfredi, "Response Prediction of R/C Beams Externally Bonded with Steel Reinforced Polymers", Journal of Composites for Construction, ASCE, vol. 103 (2), pp. 195-203, 2006.

[6] P. Casadei, A. Nanni and T. Alkhrdaji, "Steel Reinforced Polymer: an Innovative and Promising Material for Strengthening the Infrastractures", Concrete Engineering International, UK, vol. 9 (1), $54,2005$.
G. Thermou, V. Syntzirma and S. Pantazopoulou, "Seismic Retrofitting of Substandard R/C Prismatic Members Using Composite Jackets", in Proceedings of 1st European Conference on Earthquake Engineering and Seismology, Geneva, Switzerland, 2006, Paper \# 451.

[15] G. Mitolidis, T. Salonikios and A. Kappos, "Mechanical Characteristics of Carbon FRP and Steel RP and Investigation of their Efficiency for the Strengthening of R/C Beams", in Proceedings of 15th National Concrete Conference, Alexandroupolis, Greece, 2006, vol. C, pp. 347-359 (in Greek).

[16] Japan Society of Civil Engineers, "Test method for bond properties of continuous fibre sheets to concrete", JSCE-E 543-2000.

[17] H. Toutanji, P. Saxena, L. Zhao and T. Ooi, "Prediction of Interfacial Bond Failure of FRP - Concrete Surface", Journal of Composites for Construction, ASCE, vol. 11 (4), pp. 427-436, 2007. 